\title{
COVID-19 in long-term care homes in Ontario and British Columbia
}

\author{
Michael Liu AB, Colleen J. Maxwell PhD, Pat Armstrong PhD, Michael Schwandt MD MPH, \\ Andrea Moser MD MSc, Margaret J. McGregor MD MHSc, Susan E. Bronskill PhD, Irfan A. Dhalla MD MSc
}

Cite as: CMAJ 2020 November 23;192:E1540-6. doi: 10.1503/cmaj.201860; early-released September 30, 2020

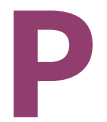

eople living in long-term care (LTC) homes in Canada have been far more likely to die of coronavirus disease 2019 (COVID-19) than the rest of the population. ${ }^{1}$ However, the effect of COVID-19 on residents in LTC has varied across provinces and territories. For example, as of Sept. 10, 2020, according to publicly available data, there were 5965 resident cases and 1817 resident deaths in Ontario LTC facilities compared to 466 cases and 156 deaths in British Columbia care facilities (Table 1). ${ }^{2,3}$ Rates of severe acute respiratory syndrome coronavirus 2 (SARS-CoV-2) infection ( $7.6 \%$ v. $1.7 \%$, respectively) and COVID-19 mortality ( $2.3 \%$ v. $0.6 \%$, respectively) among residents in LTC were several times higher in Ontario than British Columbia, although case fatality rates were similar.

We consider the reason for these differences by examining pandemic preparedness in LTC and subsequent first-wave pandemic responses in LTC in Ontario and British Columbia by means of a comparative case study (Appendix 1, available at www.cmaj.ca/lookup/doi/10.1503/cmaj.201860/tab-related -content). ${ }^{4}$ We focused on Ontario and British Columbia because these large provinces had stark differences in COVID-19 outcomes, despite similar LTC systems. Our analysis suggests that the difference in outcome has been primarily due to differential risk in residents in LTC acquiring SARS-CoV-2.

\section{What role do provinces play in the provision of long-term care?}

In Canada, LTC homes provide support and a place to live for adults who can no longer live independently. ${ }^{5}$ The Canada Health Act requires all provinces to ensure that eligible individuals do not have to pay directly for "medically necessary" physician and hospital services. ${ }^{6}$ Personal support and nursing provided in LTC homes are not covered under the Act. ${ }^{7}$ As a result, policies, funding and standards concerning LTC are decided by provincial governments. The Long-Term Care Homes Act and the Community Care and Assisted Living Act are the applicable laws in Ontario and BC, respectively. Both provinces provide funding for LTC homes, with residents also typically providing a copayment.

\section{KEY POINTS}

- Many more residents living in Ontario long-term care homes have died from coronavirus disease 2019 (COVID-19) than in British Columbia.

- Before the pandemic, the long-term care system in British Columbia exhibited a number of potential strengths relevant to pandemic preparedness compared with Ontario: there was better coordination between long-term care, public health and hospitals; greater funding of long-term care; more care hours for residents; fewer shared rooms; more nonprofit facility ownership; and more comprehensive inspections.

- During the first wave of the pandemic, British Columbia was faster than Ontario in responding to COVID-19, with actions to address public health support, staffing, and infection prevention and control.

- Leaders in British Columbia were more decisive, coordinated and consistent in their overall communication and response.

\section{How was long-term care different in Ontario and British Columbia before COVID-19?}

\section{Characteristics of residents}

Before the pandemic, the age and sex distribution of residents in LTC were similar in the 2 provinces (Table 2). ${ }^{9,10}$ Although residents living in Ontario LTC homes appear to be more medically and functionally complex, it is unclear whether these are true differences or reflect differing documentation practices, which may arise as a consequence of different funding formulas. ${ }^{15-17}$

\section{Funding, staffing and direct care hours}

In 2018-2019, the average combined funding per resident per diem was higher in British Columbia (\$222) than in Ontario (\$203). ${ }^{10,11}$ Most of this funding is used to pay staff in both provinces. ${ }^{11,14}$

Some estimates suggest that, before the pandemic, residents in British Columbia received more daily hours of direct care (3.25) than residents in Ontario (2.71). ${ }^{10,12}$ There are 
Table 1: Coronavirus disease 2019 cases and deaths among residents in long-term care facilities in Ontario and British Columbia (2020)

\begin{tabular}{lcc}
\hline & Ontario* & BC \\
\hline No. of facility outbreaks (current and resolved) & 436 & 72 \\
\hline Cumulative no. of resident cases & 5965 & 466 \\
\hline Resident infection rate, \% & 7.6 & 1.7 \\
\hline Cumulative no. of resident deaths & 1817 & 156 \\
\hline Resident mortality rate, \% & 2.3 & 0.6 \\
\hline Resident case fatality rate, \% & 30.5 & 33.5 \\
\hline $\begin{array}{l}\text { *Data up to Sept. 10, 2020, from Public Health Ontario (includes only long-term care } \\
\text { homes). } \\
\text { †Data up to Sept. 10, 2020, from BC Centre for Disease Control (includes acute care, } \\
\text { long-term care and independent living facilities). }\end{array}$ & &
\end{tabular}

currently no minimum staffing or care time requirements in either province. Several studies have shown inverse relations between staffing levels and care hours, and poor outcomes such as rates of infection and hospital admission among residents. ${ }^{18-21}$ Recent studies have also shown an association between low staffing levels and COVID-19 infections within LTC homes. ${ }^{22-24}$

Many LTC staff, in particular care aides or personal support workers, are underpaid and less likely to secure fulltime positions relative to their counterparts in other sectors of the health care system. ${ }^{25,26}$ As such, staff frequently take on several part-time or casual roles at different LTC homes, which increases the risk of transmission among facilities. Some LTC homes also subcontract out services such as laundry, cleaning and cooking, further increasing transmission risk. ${ }^{27}$ In addition, subcontracted staff may have less access to paid sick leave - a critical element in allowing staff to self-isolate when ill. All of this is in line with evidence that staff are the main vectors of SARS-CoV-2 transmission in LTC facilities. ${ }^{28-30}$ We are unaware of data that allow for comparisons of wages and rates of multisite employment between Ontario and British Columbia.

\section{Shared rooms}

Prior to the COVID-19 pandemic, LTC residents in Ontario were more likely to reside in shared rooms (63\% of residents) than those in British Columbia (24\%). ${ }^{10,13}$ In the hospital setting, rates of infection associated with health care are lower within wards featuring single-patient rooms, ${ }^{31}$ and a recent populationbased retrospective cohort study in Ontario showed that LTC residents living in shared rooms were more likely to contract SARS-CoV-2 (preprint citation). ${ }^{13}$

\section{Business models}

In both provinces, LTC homes are managed on a nonprofit or for-profit basis. More LTC homes in Ontario are managed on a for-profit basis (58\%) than in British Columbia (34\%).9,14 Existing evidence suggests that, on average, for-profit homes deliver inferior care across a variety of process and outcome

Table 2: Characteristics of residents in long-term care facilities in Ontario and British Columbia

\begin{tabular}{|lcc|}
\hline Characteristic & Ontario & BC \\
\hline Resident demographic characteristics & $(2018-2019)^{*}$ & \\
\hline Average age of residents, $y r$ & 83 & 84 \\
\hline Residents age 85 and older, \% & 54.8 & 56.0 \\
\hline Female residents, \% & 67.1 & 63.9 \\
\hline
\end{tabular}

Resident health and functioning characteristics (2018-2019), $\%$

$\begin{array}{lcc}\text { Diabetes } & 27.8 & 20.5 \\ \text { Arteriosclerotic heart disease } & 15.5 & 5.3 \\ \text { Congestive heart failure } & 12.7 & 11.2 \\ \text { Hypertension } & 64.3 & 47.6 \\ \text { Dementia } & 63.5 & 63.7 \\ \text { Depression } & 32.7 & 22.8 \\ \text { Asthma } & 4.7 & 2.4 \\ \text { Emphysema/COPD } & 15.3 & 12.0 \\ \text { ADL index hierarchy score of 3 or } & 86.1 & 73.6 \\ \text { more (extensive supervision) } & & \\ \text { CPS score of 5 or more (severe to } & 22.3 & 22.7\end{array}$

very severe impairment)

Facility characteristics (2018-2019)*

No. of beds

$\begin{array}{ll}\sim 79000 & \sim 27000 \\ (2019) \dagger & (2019) \ddagger \\ 110161 & 36829\end{array}$

Cumulative no. of residents in

110161

36829

2018-2019

Funding and direct care hours

Average funding per resident per diem, \$

203

(2018-19)§

Average direct care hours provided

$2.71(2019) \oplus$

$\$ 222$

(2018-19)‡

3.25

(2018-19)‡

Shared rooms

Residents in private (1-person)

rooms, \%

Residents in shared (2 or more

people) rooms, \%

Ownership of facilities

$\begin{array}{lcc}\text { No. of facilities } & 626(2019) \dagger & 294(2019) \ddagger \\ \text { For profit, \% } & 58(2019) \dagger & 34(2019) \dagger \dagger \\ \text { Not for profit, \% } & 42(2019) \dagger & 66(2019) \dagger \dagger\end{array}$

Note: $\mathrm{ADL}$ = activities of daily living, $\mathrm{COPD}$ = chronic obstructive pulmonary disease, CPS = Cognitive Performance Scale.

*Data from the Canadian Institute for Health Information: Profile of Residents in Residential and Hospital-Based Continuing Care, 2018-2019. ${ }^{8}$

†Data from the Ontario Long-Term Care Association: This Is Long-Term Care 2019 report. ${ }^{9}$ $\ddagger$ Data from the BC Office of the Seniors Advocate: Long-Term Care Facilities Quick Facts Directory. ${ }^{10}$ Funding figure includes resident copayments and goes toward staffing costs, food and supply costs, administration, repair and maintenance, housekeeping and landscaping services, property costs and capital.

$\S$ Data from the Financial Accountability Office of Ontario: Long-Term Care Homes Program Report. Funding figure includes resident copayments and goes toward nursing and personal care, program and support services, raw food, basic accommodation, construction funding subsidies for new or redeveloped beds, and physiotherapy and behavioural supports. ${ }^{11}$ ฯData from the BC Care Providers Association: Filling the Gap report. ${ }^{12}$

${ }^{\star \star}$ Data from Brown et al. ${ }^{13}$

$\dagger †$ Data from the BC Office of the Seniors Advocate: A Billion Reasons to Care report. ${ }^{14}$ 
measures. ${ }^{32-35}$ A preliminary retrospective cohort study of LTC homes in Ontario found that for-profit status was associated with the extent of COVID-19 outbreaks and number of resident deaths. ${ }^{36}$ The relation between profit status and outcomes is complex and mediated or confounded by several factors including staff unionization, chain ownership and availability of personal protective equipment (PPE). ${ }^{37-39}$ For example, several reports have documented that for-profit homes pay lower wages, have lower staffing levels, hire more part-time and casual workers and have more turnover than nonprofit homes. ${ }^{14,40-42}$

\section{Inspection policies}

Inspections could be important mechanisms for ensuring that LTC homes are prepared to prevent and manage infectious diseases. British Columbia requires annual and comprehensive inspections of all LTC homes by regional health authorities. Similarly, Ontario requires annual inspections of all LTC homes by the Ministry of Long-Term Care. Before 2018, almost all LTC homes in Ontario received comprehensive inspections. ${ }^{43,44}$ However, in late 2018, Ontario transitioned to a risk-based framework where narrower inspections are conducted in response to critical incidents and complaints. As a result, although there were about 2800 inspections in 2019, most were related to complaints or critical incidents, and only 9 of 626 (1.4\%) LTC homes in Ontario received a comprehensive inspection. ${ }^{45}$

\section{Health system organization}

Before the pandemic, the links between hospitals, LTC and public health were stronger in British Columbia than in Ontario. In British Columbia, 5 regional health authorities oversee health services including hospitals, public health and LTC. ${ }^{46}$ Although Ontario does have some regionalization, hospitals have their own boards of directors, and public health remains outside of governance by regional health systems. ${ }^{47}$ Instead, the public health response is overseen by 34 public health units that typically report to a municipality. ${ }^{48}$

The organizational structure of British Columbia's health system was relatively stable before the pandemic, whereas Ontario's was in a state of flux. Specifically, the regional entities in Ontario - Local Health Integration Networks (LHINs) - as well as several provincial agencies were in the process of being merged into a single agency called Ontario Health. ${ }^{49}$ Many senior leaders within LHINs and provincial agencies departed and had not yet been replaced. ${ }^{50}$ Effective health system governance and leadership are important for the delivery of high-quality care..$^{51,52}$ Relatedly, funding provided to various provincial and regional entities in British Columbia was relatively stable before the pandemic. In comparison, provincial agencies such as Public Health Ontario and individual public health units were all in the process of reducing their expenditures in response to government direction ${ }^{53}$ despite evidence that shows increased public health spending to be associated with better population health outcomes..$^{54,55}$

\section{How were the Ontario and British Columbia long-term-care responses to COVID-19 different?}

\section{Leadership and communication}

Coronavirus disease 2019 was first diagnosed in Ontario on Jan. 25, 2020, and in British Columbia on Jan. 27, 2020.56 Through daily briefings and media interviews, the Provincial Health Officer of British Columbia and elected leaders delivered consistent messages about the state of the pandemic and public health recommendations. ${ }^{57}$ In Ontario, communication was less coordinated, with elected leaders and the Chief Medical Officer of Health sometimes conveying conflicting messages in separate briefings. ${ }^{58}$

\section{Staffing}

Orders that limited and supported staff in working at a single home were intended to reduce SARS-CoV-2 transmission among LTC homes. British Columbia announced a single-site LTC work policy on Mar. 26, 2020, whereas Ontario did not announce such a policy until Apr. 14, 2020.59,60 On Mar. 31, 2020, British Columbia took measures to promote full-time work and standardized wages for all staff. ${ }^{61}$ Ontario's Action Plan: Responding to COVID-19 suggested that LTC homes bring part-time staff to full-time hours on Apr. 15, 2020.62 On Apr. 25, 2020 , Ontario also announced that it would offer a $\$ 4$ an hour pandemic pay bump to front-line workers, including LTC staff. However, even by June 2020, many front-line workers had not yet received their pandemic pay. ${ }^{63}$

As COVID-19 overwhelmed some LTC homes throughout April and May of 2020, Ontario began taking drastic measures. ${ }^{64}$ This included calling in the military to assist high-risk LTC homes and appointing hospitals to manage certain homes. These measures were not needed in British Columbia.

\section{Infection prevention and control}

Starting as early as the first outbreak in an LTC home on Mar. 7, 2020, regional health authorities in British Columbia sent specialized health teams comprising infection control practitioners, public health staff and clinicians to all homes with outbreaks under their governance, irrespective of facility ownership. ${ }^{65}$ These teams assisted with all aspects of infection prevention and control, from providing PPE to testing residents. Some LTC homes in Ontario were able to access similar support for infection prevention and control early on, particularly if they were associated with hospitals. ${ }^{66}$ However, it was not until Apr. 15, 2020, that Ontario started working with public health units and hospitals to assemble similar teams to support all LTC homes in need. ${ }^{62}$

Another key response was that British Colimbia revised its threshold of an outbreak to a single case among LTC residents or staff early on. ${ }^{67}$ This definition was used by one of the regional health authorities to declare an outbreak on Mar. 18, 2020, and was quickly incorporated into provincial guidelines. Ontario did not similarly revise its definition of an outbreak until Apr. 15, 2020. ${ }^{68}$

Although initial testing policies in both provinces focused on symptomatic residents, specialized health teams in British 
Columbia were also screening asymptomatic residents in LTC homes with outbreaks in March and April of 2020.69,70 Formal guidance to test all LTC residents and staff in Ontario came later on Apr. 22, 2020. ${ }^{71}$

Universal masking is another important measure of infection prevention and control that reduces SARS-CoV-2 transmission. ${ }^{72}$ On Mar. 25, 2020, British Columbia issued a directive that all LTC staff and visitors should wear masks within LTC homes. ${ }^{73}$ Ontario did not provide similar directives until Apr. 8, 2020. ${ }^{62}$

\section{Visitor policies}

Given that SARS-CoV-2 can be transmitted by asymptomatic individuals, limiting visits to LTC homes was considered an important measure for infection prevention and control early in the pandemic. ${ }^{74}$ Ontario and British Columbia announced visitor restrictions on Mar. 13 and 16, 2020, respectively. However, visitor restrictions often result in less direct care, social isolation and decreased well-being. ${ }^{75-77}$ Efforts are needed to determine how LTC residents can safely interact with loved ones during an infectious disease outbreak.

\section{How can Canadian jurisdictions be better prepared for future outbreaks in long-term care?}

Several baseline differences in the LTC sector may have contributed to better COVID-19 outcomes in British Columbia than in Ontario. Before the pandemic, British Columbia had more coordination between LTC, hospitals and public health, greater funding of LTC with more care hours for residents, fewer shared rooms within LTC homes, more nonprofit facility ownership and more comprehensive inspections.

During the first wave of the pandemic, in many areas, British Columbia responded to COVID-19 faster than Ontario, being several weeks ahead of Ontario in announcing a singlesite LTC work policy, deploying specialized health teams to LTC homes with outbreaks, directing the use of universal masking and reducing the threshold for outbreak declaration. Even short delays may have had a substantial effect on COVID19 burden given the nature of exponential growth. ${ }^{78,79}$ In addition to being slower, the nature of some responses in Ontario may have contributed to worse outcomes. For example, Ontario provided LTC homes with operational flexibility in late March, 2020, and allowed them to rely more heavily on contractors, nonunionized employees and volunteers. Lack of appropriate experience and training in infection prevention and control among these staff could have compromised resident safety and increased SARS-CoV-2 transmission. ${ }^{80}$

It is important to note that our analysis focused primarily on province-level LTC characteristics and responses. In both Ontario and British Columbia, local responses and outcomes have varied. For example, one public health unit in Ontario deployed inspectors to every LTC home in its jurisdiction in early March to ensure that all had testing plans, enough PPE and appropriate outbreak management plans. ${ }^{81}$ To date, there have been no deaths in LTC in that region. Moreover, some
Ontario LTC homes had particularly engaged medical directors or were supported by additional physicians from the community, whereas other LTC homes had minimal physician presence. ${ }^{80,82}$ Another limitation of our analysis is that residents in LTC in British Columbia may have fared better, in part, because the overall COVID-19 burden has been larger in Ontario. Unsurprisingly, a recent study identified an association between outbreak risk and incidence of COVID-19 in the area surrounding an LTC home in Ontario. ${ }^{36}$ Still, our analysis suggests that there were important differences before and during the pandemic that were specific to the LTC sector.

Our findings support policy briefings from the Restoring Trust: COVID-19 and The Future of Long-Term Care report by the Royal Society of Canada (Box 1). ${ }^{26}$ Our comparison between Ontario and British Columbia also suggests additional policy briefings for policy-makers to consider. First, elected and public health officials should communicate clearly and consistently with the public in a manner that generates and maintains broad support. Second, leaders should respond quickly with proactive and decisive measures. Third, governments should ensure that staffing, facility characteristics and other known mediators of observed profit-status disparities do not result in differences in the quality of care provided in for-profit and nonprofit homes. Fourth, policy-makers should implement single-room design standards for new LTC homes and consider how to transition existing homes away from shared rooms. Fifth, governments and public health

Box 1: Coronavirus disease 2019 (COVID-19) long-term care policy recommendations adapted with permission from Restoring Trust: COVID-19 and The Future of LongTerm Care $^{26}$

- All long-term care (LTC) homes must have comprehensive plans for preventing and managing infectious disease outbreaks.

- Public health units must conduct regular and unannounced inspections to ensure that plans are being implemented appropriately.

- Provincial governments must manage procurement to ensure LTC homes have adequate personal protective equipment (PPE), and everyone who comes in contact with residents in LTC homes should be adequately trained in proper usage of PPE and infection prevention and control measures.

- Staff at long-term care homes must have the option for full-time work with equitable wages, benefits and pandemic work supports including sick leave and mental health support.

- One-site work policies should continue throughout and after the pandemic.

- All LTC homes must have the capacity to isolate residents in the event of an outbreak. Where this is not possible, residents should be transferred to a hospital or another setting where isolation is feasible.

- Plans should ensure that technology and other means facilitate continued connection between isolated residents and loved ones. This should include continued visits from designated family and friends who are supported with appropriate PPE and education about infection prevention and control. 
organizations should ensure that teams trained in infection prevention and control are available to support LTC homes during outbreaks. Finally, governments should consider what organizational structures are required to provide sufficient integration between LTC, public health and hospitals.

Residents in long-term care homes will always be vulnerable to infectious pathogens. Our analysis has highlighted policies and practices that could help protect these residents from a second COVID-19 wave or future pandemics. The experience to date suggests that better preparedness and responses could save the lives of thousands of people living in LTC homes in Canada.

\section{References}

1. Comas-Herrera A, Zalakaín J, Litwin C, et al. Mortality associated with COVID19 outbreaks in care homes: early international evidence. International LongTerm Care Policy Network; updated 2020 June 26. Available: https://tccovid. org/2020/04/12/mortality-associated-with-covid-19-outbreaks-in-care-homes -early-international-evidence/ (accessed 2020 July 31).

2. Ontario Agency for Health Protection and Promotion (Public Health Ontario). Epidemiologic summary: COVID-19 in Ontario - January 15, 2020 to September 10, 2020. Toronto: Queen's Printer for Ontario; 2020.

3. BC COVID-19 data. Vancouver: BC Centre for Disease Control; 2020. Available: www. bccdc.ca/Health-Info-Site/Documents/BC_Surveillance_Summary_Sept_10_2020.pdf (accessed 2020 Sept. 12).

4. Goodrich D. Comparative case studies. Methodological Briefs Impact Evaluation No. 9. Florence (Italy): UNICEF Office of Research - Innocenti; 2014.

5. $\mathrm{Ng} \mathrm{R}$, Lane $\mathrm{N}$, Tanuseputro $\mathrm{P}$, et al. Increasing complexity of new nursing home residents in Ontario, Canada: a serial cross-sectional study. J Am Geriatr Soc 2020;68:1293-300.

6. Armstrong P, Armstrong H. Decentralised health care in Canada. BMJ 1999; 318:1201-4.

7. Chan P, Kenny SR. National consistency and provincial diversity in delivery of long-term care in Canada. J Aging Soc Policy 2001;13:83-99.

8. Profile of residents in residential and hospital-based continuing care, 2018-2019. Ottawa: Canadian Institute for Health Information. Available: www.cihi.ca/en/ profile-of-residents-in-residential-and-hospital-based-continuing-care-2018-2019 (accessed 2020 July 17).

9. This is long-term care 2019: the impact of dementia; new evidence about quality care; the need for more staff. Toronto: Ontario Long Term Care Association; 2019. Available: www.oltca.com/OLTCA/Documents/Reports/TILTC2019web. pdf (accessed 2020 July 17).

10. Long-term care facilities quick facts directory. 5th ed. Victoria: Office of the Seniors Advocate; 2019. Available: www.seniorsadvocatebc.ca/app/uploads/ sites/4/2019/09/QuickFacts2019-Summary.pdf (accessed 2020 July 17).

11. Long-term care homes program: a review of the plan to create 15,000 new long-term care beds in Ontario. Toronto: Financial Accountability Office of Ontario; 2019. Available: www.fao-on.org/web/default/files/publications/ FA1810\%20Long-term\%20Care\%20Bed\%20Expansion\%20Analysis/Longterm-care-homes\%20program.pdf (accessed 2020 July 17).

12. Filling the gap: determining appropriate staffing and care levels for quality in long-term care. Burnaby (BC): BC Care Providers Association; 2019. Available: https://bccare.ca/wp-content/uploads/2019/03/Filling-the-Gap-March-2019. pdf (accessed 2020 July 17).

13. Brown KA, Jones A, Daneman N, et al. Association between nursing home crowding and COVID-19 infection and mortality in Ontario, Canada. medRxiv 2020 June 23. doi: 10.1101/2020.06.23.20137729.

14. A billion reasons to care: a funding review of contracted long-term care in B.C. Victoria: Office of the Seniors Advocate; 2020. Available: www.seniorsadvocatebc.ca/ app/uploads/sites/4/2020/02/ABillionReasonsToCare.pdf (accessed 2020 July 17).
15. Armstrong H, Daly TJ, Choiniere JA. Policies and practices: the case of RAI-MDS in Canadian long-term care homes. J Can Stud 2016;50:348-67.

16. Steinbusch PJM, Oostenbrink JB, Zuurbier JJ, et al. The risk of upcoding in casemix systems: a comparative study. Health Policy 2007;81:289-99.

17. Residential care staffing review. Victoria: BC Ministry of Health; 2017. Available: www.health.gov.bc.ca/library/publications/year/2017/residential-care-staffing -review.pdf (accessed 2020 Sept. 15).

18. Armijo-Olivo S, Craig R, Corabian $\mathrm{P}$, et al. Nursing staff time and care quality in long-term care facilities: a systematic review. Gerontologist 2020;60:e200-17.

19. Schnelle JF, Simmons SF, Harrington C, et al. Relationship of nursing home staffing to quality of care. Health Serv Res 2004;39:225-50.

20. Boscart VM, Sidani S, Poss J, et al. The associations between staffing hours and quality of care indicators in long-term care. BMC Health Serv Res 2018;18:750.

21. Konetzka RT, Stearns SC, Park J. The staffing-outcomes relationship in nursing homes. Health Serv Res 2008;43:1025-42.

22. Li Y, Temkin-Greener H, Gao S, et al. COVID-19 infections and deaths among Connecticut nursing home residents: facility correlates. J Am Geriatr Soc 2020 June 18 [Epub ahead of print]. doi: 10.1111/jgs.16689.

23. Harrington C, Ross L, Chapman S, et al. Nurse staffing and coronavirus infections in California nursing homes. Policy Polit Nurs Pract 2020;21:174-86.

24. Gorges RJ, Konetzka RT. Staffing levels and COVID-19 cases and outbreaks in U.S. nursing homes. J Am Geriatr Soc 2020 Aug. 8 [Epub ahead of print]. doi: $10.1111 /$ jgs.16787.

25. Holroyd-Leduc JM, Laupacis A. Continuing care and COVID-19: a Canadian tragedy that must not be allowed to happen again. CMAJ 2020;192:E632-3.

26. Estabrooks CA, Straus S, Flood CM, et al. Restoring trust: COVID-19 and the future of long-term care. Ottawa: Royal Society of Canada; 2020. Available: https://rsc-src.ca/en/restoring-trust-covid-19-and-future-long-term-care (accessed 2020 July 16).

27. Armstrong $\mathrm{P}$, Armstrong $\mathrm{H}$, Choiniere J, et al. Re-imagining long-term residential care in the COVID-19 crisis. Ottawa: Canadian Centre for Policy Alternatives; 2020.

28. Fisman DN, Bogoch I, Lapointe-Shaw L, et al. Risk factors associated with mor tality among residents with coronavirus disease 2019 (COVID-19) in long-term care facilities in Ontario, Canada. JAMA Netw Open 2020;3:e2015957.

29. Roxby AC, Greninger AL, Hatfield KM, et al. Outbreak investigation of COVID19 among residents and staff of an independent and assisted living community for older adults in Seattle, Washington. JAMA Intern Med 2020;180:1101-5.

30. Chow EJ, Schwartz NG, Tobolowsky FA, et al. Symptom screening at illness onset of health care personnel with SARS-CoV-2 infection in King County, Washington. JAMA 2020;323:2087-9.

31. Stiller A, Salm F, Bischoff P, et al. Relationship between hospital ward design and healthcare-associated infection rates: a systematic review and meta-analysis. Antimicrob Resist Infect Control 2016;5:51.

32. Comondore VR, Devereaux PJ, Zhou Q, et al. Quality of care in for-profit and not-for-profit nursing homes: systematic review and meta-analysis. BMJ 2009;339:b2732.

33. Tanuseputro $\mathrm{P}$, Chalifoux M, Bennett $\mathrm{C}$, et al. Hospitalization and mortality rates in long-term care facilities: Does for-profit status matter? J Am Med Dir Assoc 2015;16:874-83.

34. Castle NG, Wagner LM, Ferguson-Rome JC, et al. Nursing home deficiency citations for infection control. Am J Infect Control 2011;39:263-9.

35. Castle N, Wagner L, Ferguson J, et al. Hand hygiene deficiency citations in nursing homes. J Appl Gerontol 2014;33:24-50.

36. Stall NM, Jones A, Brown KA, et al. For-profit long-term care homes and the risk of COVID-19 outbreaks and resident deaths. CMAJ 2020;192:E946-55.

37. McGregor MJ, Harrington C. COVID-19 and long-term care facilities: Does ownership matter? CMAJ 2020;192:E961-2.

38. Figueroa JF, Wadhera RK, Papanicolas I, et al. Association of nursing home ratings on health inspections, quality of care, and nurse staffing with COVID-19 cases. JAMA 2020;324:1103-5. 
39. Dean A, Venkataramani A, Kimmel S. Mortality rates from COVID-19 are lower in unionized nursing homes. Health Aff (Millwood) 2020 Sept. 10 [Epub ahead of print]. doi: 10.1377/hlthaff.2020.01011.

40. McGregor MJ, Cohen M, McGrail K, et al. Staffing levels in not-for-profit and forprofit long-term care facilities: Does type of ownership matter? CMAJ 2005;172:645-9.

41. Ronald LA, McGregor MJ, Harrington C, et al. Observational evidence of forprofit delivery and inferior nursing home care: When is there enough evidence for policy change? PLoS Med 2016;13:e1001995.

42. Harrington C, Swan JH. Nursing home staffing, turnover, and case mix. Med Care Res Rev 2003;60:366-92, discussion 393-9.

43. The Long-Term Care Homes Public Inquiry. Public inquiry into the safety and security of residents in the long-term care homes system. Toronto: Queen's Printer for Ontario; 2019.

44. Long-term care in Ontario: sector overview. Health Analytics Branch, Health System Information Management and Investment Division, Ministry of Health and Long-Term Care; 2015.

45. Pedersen K, Mancini M, Common D. Ontario scaled back comprehensive, annual inspections of nursing homes to only a handful last year. CBC News updated $2020 \mathrm{Apr}$. 15. Available: www.cbc.ca/news/canada/seniors-homes -inspections-1.5532585 (accessed 2020 July 9).

46. Health Funding Explained 2. Victoria: Office of the Auditor General of British Columbia; 2017. Available: www.bcauditor.com/sites/default/files/publications/ reports/FINAL_HFE2_2.pdf (accessed 2020 Sept. 11).

47. Moloughney B. A discussion paper on public health, local health integration networks, and regional health authorities. Toronto: Ontario Public Health Association; 2007.

48. Lyons J. The independence of Ontario's public health units: Does governing structure matter? Healthc Policy 2016;12:71-83.

49. D'Mello C. Ontario postpones part of its health care overhaul due to COVID-19. CTV News Toronto updated 2020 Mar. 18. Available: https://toronto.ctvnews. ca/ontario-postpones-part-of-its-health-care-overhaul-due-to-covid-19 -1.4858008 ? cache=tzbrsjtr\%3FcontactForm\%3Dtrue\%3FautoPlay\%3Dtrue\% 3Fclipld\%3D89750\%3FautoPlay\%3Dtrue (accessed 2020 July 20).

50. Warnica R. Public Health Ontario suffered exodus of senior leaders and budget cuts before the COVID-19 pandemic struck. National Post [Toronto]. Available: https://nationalpost.com/news/canada/covid-19-public-health-ontario-budget -cuts (accessed 2020 July 20).

51. Greer SL, Wismar M, Figueras J, editors. Strengthening health system governance: better policies, stronger performance - European Observatory on Health Systems and Policies Series. Geneva: World Health Organization; 2016.

52. Sfantou DF, Laliotis A, Patelarou AE, et al. Importance of leadership style towards quality of care measures in healthcare settings: a systematic review. Healthcare (Basel) 2017;5:73.

53. Pelley L. Clinicians, health advocates ringing alarms about province's 'shortsighted' cuts to public health. CBC News updated 2019 Apr. 15. Available: www. cbc.ca/news/canada/toronto/clinicians-health-advocates-ringing-alarms -about-province-s-short-sighted-cuts-to-public-health-1.5098936 (accessed 2020 July 20).

54. Singh SR. Public health spending and population health: a systematic review. Am J Prev Med 2014;47:634-40.

55. Mays GP, Smith SA. Evidence links increases in public health spending to declines in preventable deaths. Health Aff (Millwood) 2011;30:1585-93.

56. The Canadian Press. Coronavirus: here's a timeline of COVID-19 cases in Canada. Global News 2020 May 3, updated 2020 Mar. 6. Available: https:// globalnews.ca/news/6627505/coronavirus-covid-canada-timeline/ (accessed 2020 July 9).

57. Porter $\mathrm{C}$. The top doctor who aced the coronavirus test. The New York Times 2020 June 6. Available: www.nytimes.com/2020/06/05/world/canada/bonnie -henry-british-columbia-coronavirus.html (accessed 2020 July 22).

58. Weeks C. How the provinces differ when it comes to messaging on COVID-19. Globe and Mail [Toronto] 2020 Mar. 17. Available: www.theglobeandmail.com/ canada/article-how-the-provinces-differ-when-it-comes-to-messaging-on -covid-19/ (accessed 2020 July 22).
59. O. Reg. 146/20: Limiting work to a single long-term care home. Under the Reopening Ontario (A Flexible Response to COVID-19) Act, S.O. 2020, c. 17. Available: www.ontario.ca/laws/regulation/200146 (accessed 2020 Sept. 12).

60. Re: Long Term care facility staff movement limitation. Victoria: Office of the Provincial Health Officer. Available: www2.gov.bc.ca/assets/gov/health/ about-bc-s-health-care-system/office-of-the-provincial-health-officer/reports -publications/covid-19-pho-order-movement-health-care-staff.pdf (accessed 2020 Sept. 12).

61. Hager M, Woo ABC. Health officer takes over nursing-home staffing as coronavirus spreads. Globe and Mail [Toronto] 2020 Mar. 31, updated 2020 Apr. 2. Available: www.theglobeandmail.com/canada/british-columbia/article-bc -health-officer-takes-over-nursing-home-staffing-as-coronavirus/ (accessed 2020 Sept. 12).

62. COVID-19 action plan: long-term care homes. Version 1 - April 15, 2020. Government of Ontario; 2020. Available: www.ontario.ca/page/covid-19-action -plan-long-term-care-homes (accessed 2020 Sept. 12).

63. Payne E. Frontline workers have yet to receive pandemic pay. Ottawa Sun 2020 July 18. Available: https://ottawasun.com/news/local-news/frontline-workers -have-still-not-received-pandemic-pay/wcm/cddad652-e1f2-4faa-b347 -2f7c58a235ff (accessed 2020 Sept. 12).

64. McIntosh E. Ontario calls on military for help as COVID-19 ravages long-term care. Canada's National Observer 2020 Apr. 22. Available: www.nationalobserver. com/2020/04/22/news/ontario-calls-military-help-covid-19-ravages-long-term-care (accessed 2020 Sept. 12).

65. Culbert L. COVID-19's early days 'really scary' at Lynn Valley home, which is now virus-free. Vancouver Sun 2020 May 6. Available: https://vancouversun. com/news/local-news/covid-19-outbreak-declared-over-at-lynn-valley-the -hardest-hit-seniors-home-in-b-c (accessed 2020 July 9).

66. Eckardt P, Guran R, Hennemyre J, et al. Hospital affiliated long term care facility COVID-19 containment strategy by using prevalence testing and infection control best practices. Am J Infect Control 2020 July 3 [Epub ahead of print]. doi: 10.1016/j.ajic.2020.06.215.

67. Yoshida-Butryn C. Confirmed case of COVID-19 at another B.C. care home. CTV News Vancouver 2020 Mar. 18. Available: https://bc.ctvnews.ca/confirmed -case-of-covid-19-at-another-b-c-care-home-1.4858574 (accessed 2020 Sept. 12).

68. COVID-19 outbreak guidance for long-term care homes (LTCH). Toronto: Ontario Ministry of Health; 2020. Available: www.health.gov.on.ca/en/pro/programs/ publichealth/coronavirus/docs/LTCH_outbreak_guidance.pdf (accessed 2020 Sept. 12).

69. BCCDC Public Health Laboratory. Laboratory guidance for patients suspected of being infected with the novel coronavirus which originated in Wuhan, China (2019-nCoV) as of Jan. 25, 2020. Vancouver: BC Centre for Disease Control; 2020. Available: www.bccdc.ca/Health-Professionals-Site/Documents/PHSA-labtesting -archived-summary.pdf (accessed 2020 Sept. 16).

70. COVID-19 Directive \#3 for long-term care homes under the Long-Term Care Homes Act, 2007. Section 77.7 of the Health Protection and Promotion Act (HPPA), R.S.O. 1990, c. H.7. Toronto: Ontario Hospital Association; 2020. Available: www.oha. com/Bulletins/CMOH Directive 3 - Long-Term Care Homes - HPPA 03302020 Shared.pdf (accessed 2020 Sept. 16).

71. D'Mello C. Ontario to begin 'proactive' testing for all long-term care residents one month into COVID-19 outbreak. CTV News Toronto 2020 Apr. 22, updated 2020 Apr. 23. Available: https://toronto.ctvnews.ca/ontario-to-begin-proactive-testing -for-all-long-term-care-residents-one-month-into-covid-19-outbreak-1.4906755 (accessed 2020 Sept. 13).

72. Wang X, Ferro EG, Zhou G, et al. Association between universal masking in a health care system and SARS-CoV-2 positivity among health care workers. JAMA 2020;324:703-4.

73. Provincial COVID-19 Task Force. COVID-19: emergency prioritization in a pandemic personal protective equipment (PPE) allocation framework. Vancouver: BC Centre for Disease Control, BC Ministry of Health; 2020. Available: www. bccdc.ca/Health-Professionals-Site/Documents/COVID19_ppe_allocation_ framework.pdf (accessed 2020 Sept. 12).

74. Rothe C, Schunk M, Sothmann P, et al. Transmission of 2019-nCOV infection from an asymptomatic contact in Germany. N Engl J Med 2020;382:970-1. 
75. Stall NM, Johnstone J, McGeer AJ, et al. Finding the right balance: an evidenceinformed guidance document to support the re-opening of Canadian nursing homes to family caregivers and visitors during the COVID-19 pandemic. J Am Med Dir Assoc 2020 Aug. 3 [Epub ahead of print]. doi: 10.1016/j. jamda.2020.07.038.

76. Gaugler JE. Family involvement in residential long-term care: a synthesis and critical review. Aging Ment Health 2005;9:105-18.

77. Jenq GY, Mills JP, Malani PN. Preventing COVID-19 in assisted living facilities a balancing act. JAMA Intern Med 2020;180:1106-7.

78. Leung K, Wu JT, Liu D, et al. First-wave COVID-19 transmissibility and severity in China outside Hubei after control measures, and second-wave scenario planning: a modelling impact assessment. Lancet 2020;395:1382-93.

79. Flaxman S, Mishra S, Gandy A, et al. Estimating the effects of non-pharmaceutical interventions on COVID-19 in Europe. Nature 2020;584:257-61.

80. Mialkowski CJJ. OP Laser - JTFC observations in long-term care facilities in Ontario. Canadian Armed Forces; Macleans 2020 May 14. Available: www. macleans.ca/wp-content/uploads/2020/05/JTFC-Observations-in-LTCF-in-ON. pdf (accessed 2020 July 9).

81. Mazur A. Kingston's long-term care COVID-19 inspection initiative a 'big win': public health. Global News 2020 Apr. 23. Available: https://globalnews.ca/ news/6859843/kingstons-long-term-care-covid-19-inspections/ (accessed 2020 July 9$)$.

82. Grill A. Family physician leadership in long-term care: COVID-19 success and a call to action. CMAJ Blogs 2020 May 28. Available: https://cmajblogs.com/family -physician-leadership-in-long-term-care-covid-19-success-and-a-call-to-action/ (accessed 2020 July 20).

Competing interests: Margaret MacGregor is a member of the board of the Vancouver Coastal Health Authority. Andrea Moser is the Associate Medical Director for The Apotex Centre, The Jewish Home for the Aged, Toronto, Ont. She is also the Chief Medical Information Officer for Baycrest Health Sciences, Toronto, Ont., and is the Chief Medical Consultant for Sienna Senior Living. No other competing interests were declared.

This article has been peer reviewed.

Affiliations: Harvard Medical School (Liu), Boston, Mass.; Department of Social Policy and Intervention (Liu), University of Oxford, Oxford, UK; Schools of Pharmacy and Public Health and Health Systems (Maxwell), University of Waterloo, Waterloo, Ont.; ICES Central (Maxwell, Bronskill); Department of Sociology (Armstrong), York University; Department of Family and Community Medicine (Moser); Institute of Health Policy, Management and Evaluation (Bronskill, Dhalla), Dalla Lana School of Public Health, and Department of Medicine (Dhalla), University of Toronto; Baycrest Health Sciences (Moser); Unity Health Toronto (Dhalla), Toronto, Ont.; Faculty of Medicine (Schwandt), School of Population and Public Health, and Department of Family Practice (McGregor), University of British Columbia; Vancouver Coastal Health (Schwandt); Vancouver, BC

Contributors: Michael Liu and Irfan Dhalla drafted the manuscript. All of the authors contributed to the conception and design of the work, revised it critically for important intellectual content, gave final approval of the version to be published and agreed to be accountable for all aspects of the work.

Acknowledgements: The authors thank Sharon Straus and Tara Kiran for providing thoughtful feedback on earlier versions of this article.

Correspondence to: Michael Liu, michael.liu@st-hildas.ox.ac.uk 